\title{
Design and Performance Investigation of a Low Cost Portable Ventilator for COVID-19 Patients
}

\author{
Mustefa Jibril ${ }^{1}$, Messay Tadese ${ }^{2}$, Nuriye Hassen ${ }^{3}$ \\ ${ }^{1}$ Msc, School of Electrical \& Computer Engineering, Dire Dawa Institute of Technology, Dire Dawa, \\ Ethiopia \\ ${ }^{2}$ Msc, School of Electrical \& Computer Engineering, Dire Dawa Institute of Technology, Dire Dawa, \\ Ethiopia \\ ${ }^{3}$ Msc, School of Electrical \& Computer Engineering, Dire Dawa Institute of Technology, Dire Dawa, \\ Ethiopia \\ mustefa.jibril@ddu.edu.et
}

\begin{abstract}
In this paper, the design of a low cost portable ventilator with performance analysis have been done to solve the scarcity of respiratory ventilators for COVID-19 patients. The materials used to build the system are: DC motor, rotating disc and pneumatic piston. The system input is the patient heart beat and the output is volume of air to the patient lung with adjusted breathing rate. This ventilator adjusts the breathing rate to the patient depending on his heart beat rate. The performance analysis of this system have been done using Proportional Integral Derivative (PID) and Full State Feedback H2 controllers. Comparison of the system with the proposed controllers have been done using a step change and a random change of the patient heart beat and a promising result have been analyzed successfully.
\end{abstract}

Keywords: Ventilator, COVID-19, DC motor, Proportional Integral Derivative, Full State Feedback $\mathrm{H} 2$ controller

\section{Introduction}

A ventilator is a machine that provides mechanical ventilation by stirring breathable air into and out of the lungs, to deliver air to a patient who is physically unable to breathe, or breathing insufficiently. Modern respirator are computerized microprocessor-controlled systems, but patients can also be ventilated with a simple, hand-operated bag valve mask. Ventilators are chiefly used in intensive-care medicine, abode care, and emergency medication (as standalone units) and in anesthesiology (as a component of an anesthesia systems). Ventilators are sometimes called "respirators", a term commonly used for them in the 1950s (particularly the "Bird respirator"). However, contemporary hospital and medical dictionary uses the phrase " respirator" to refer to a protective face-mask. Modern respirator are electronically controlled by a small embedded design to allow exact rendering of weight and flow timber to an individual patient's needs. Fine-tuned respirator settings also serve to make freshening more tolerable and comfortable for the patient.

\section{Mathematical Modeling of the ventilator}

The design of the simple ventilator is shown in Figure 1 below. The DC motor rotates the disc at angular displacement theta and this angle is converted to a linear displacement $\mathrm{x}$. This 
displacement pushes the piston back and forth so that the air will be entered to lung and gets out. The mathematical modeling system is shown below.

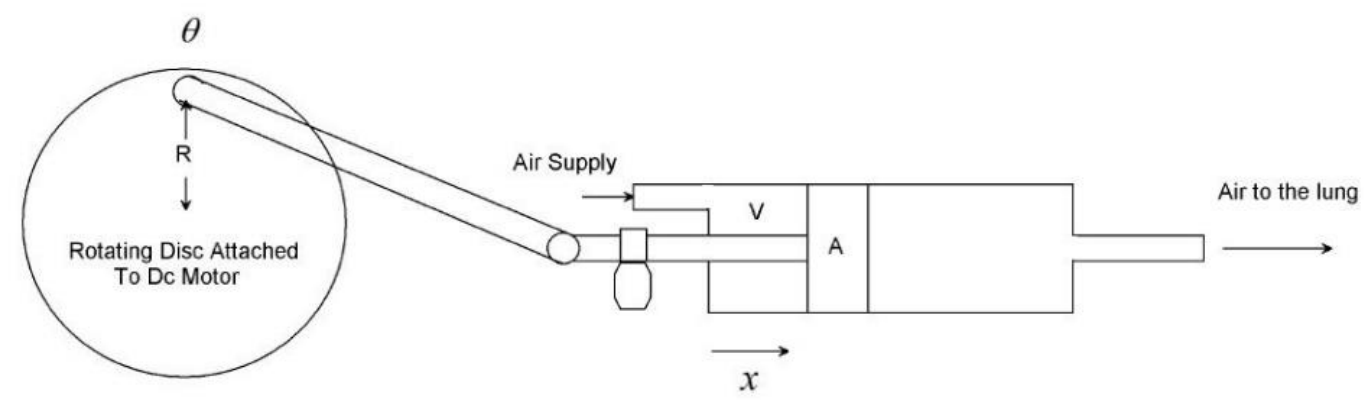

Figure 1 Respiratory ventilator system design

The DC motor transfer function between the input voltage and the angular displacement output is simply

$$
G_{m}(s)=\frac{\theta(s)}{E(s)}=\frac{K_{T}}{J L_{a} s^{3}+\left(R_{a} J+L_{a} B\right) s^{2}+\left(R_{a} B+K_{b} K_{T}\right) s}
$$

Where

$K_{T}$ torque constant of the motor having units $\mathrm{Nm} / \mathrm{A}$.

$J$ total inertia of the motor

$B$ damping coefficient of the motor

$K_{b}$ voltage constant of the motor

$R_{a}$ armature resistance

$L_{a}$ armature inductance

The displacement that the piston moves is simply

$$
X(s)=R \theta(s)
$$

The volume of air enters to the patient lung is simply the area of the piston A multiplied by the piston displacement $\mathrm{X}$

$$
V(s)=X(s) A
$$

The rate of volume enters to the patient lung is the derivative of the volume of the piston 


$$
\operatorname{Br}(s)=s V(s)
$$

Substituting Equation (2) and Equation (3) in to Equation (4) yields

$$
\operatorname{Br}(s)=s R A \theta(s)
$$

Substituting Equation (5) into Equation (1) yields to the transfer function between the motor voltage input to the breathing rate output as

$$
\frac{B_{r}(s)}{E(s)}=\frac{R K_{T} A}{J L_{a} s^{2}+\left(R_{a} J+L_{a} B\right) s+\left(R_{a} B+K_{b} K_{T}\right)}
$$

The block diagram of the ventilator is shown in Figure 2 below.

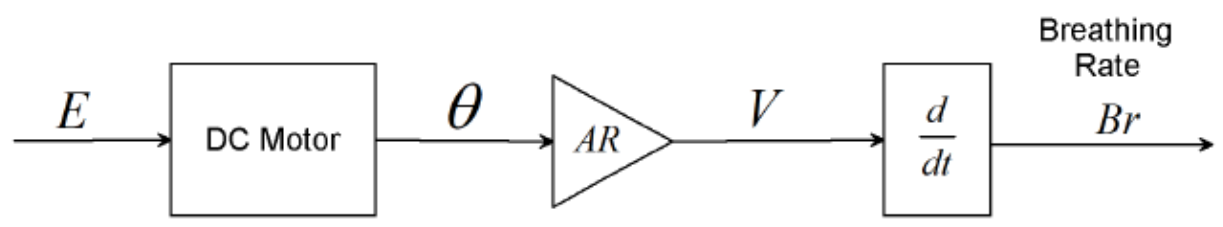

Figure 2 Block diagram of the ventilator

The parameters of the ventilator are shown in Table 1 below.

Table 1 System parameters

\begin{tabular}{|c|c|c|c|}
\hline No & Parameters & Symbol & Value \\
\hline 1 & Torque constant of the motor & $K_{T}$ & $20 \mathrm{Nm} / \mathrm{A}$ \\
\hline 2 & total inertia of the motor & $J$ & $1.25 \mathrm{Kgm} \wedge 2 / \mathrm{s}^{\wedge} 2$ \\
\hline 3 & damping coefficient of the motor & $B$ & $2.5 \mathrm{Nms}$ \\
\hline 4 & voltage constant of the motor & $K_{b}$ & $0.8 \mathrm{~V} \cdot \mathrm{rad} / \mathrm{s}^{\wedge} 2$ \\
\hline 5 & Armature resistance & $R_{a}$ & $50 \mathrm{ohm}$ \\
\hline 6 & Armature inductance & $L_{a}$ & $6.25 \mathrm{H}$ \\
\hline 7 & Disc length & $R$ & $0.3 \mathrm{~m}$ \\
\hline 8 & Piston Area & $A$ & $0.4 \mathrm{~m} \mathrm{~m}^{\wedge}$ \\
\hline
\end{tabular}

The transfer function becomes

$$
\frac{B_{r}(s)}{E(s)}=\frac{2.4}{7.8 s^{2}+78.2 s+141}
$$

With state space representation 


$$
\begin{aligned}
& \dot{x}=\left(\begin{array}{cc}
-10.0256 & -18.0769 \\
1 & 0
\end{array}\right) x+\left(\begin{array}{l}
1 \\
0
\end{array}\right) u \\
& y=\left(\begin{array}{ll}
0 & 0.3077
\end{array}\right) x
\end{aligned}
$$

The closed loop system block diagram is shown in Figure 3 below.

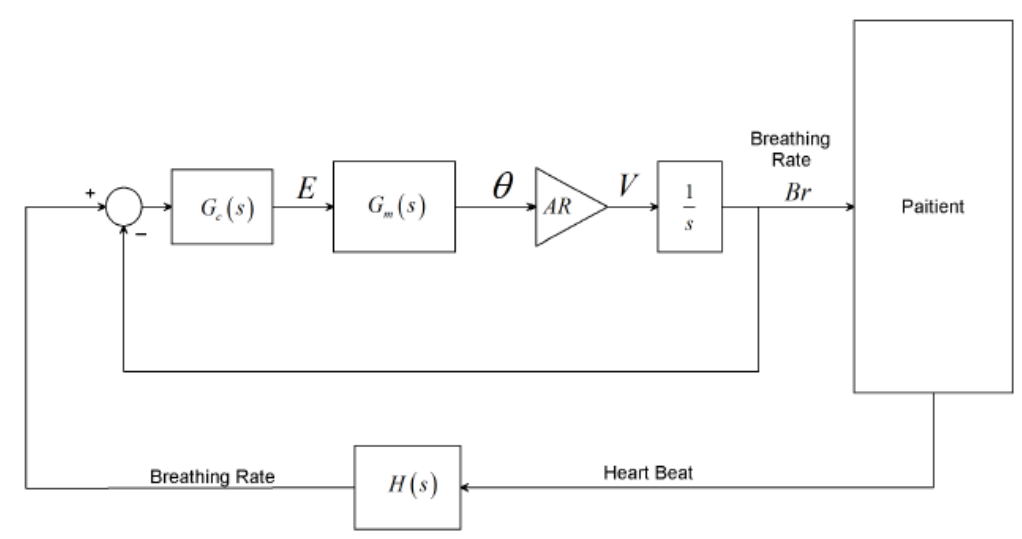

Figure 3 Closed loop system block diagram

The normal heart beat of an adult person is

$$
H_{B}=1.2 \frac{\text { Beats }}{s}
$$

The average normal breath rate of an adult person is

$$
B_{R}=0.25 \frac{\text { Breath }}{s}
$$

Table 2 shows the heart beat rate and breathing rate of an adult human being before and after activity

Table 2 heart beat rate and breathing rate of an adult human being

\begin{tabular}{|l|l|l|l|}
\hline No & Activity & $\begin{array}{l}\text { Heart beat rate } \\
(\text { Beats/s })\end{array}$ & $\begin{array}{l}\text { Breathing rate } \\
\left(\mathrm{m}^{\wedge} 3 / \mathrm{s}\right)\end{array}$ \\
\hline 1 & Before activity & 1.73 & 0.000467 \\
\hline 2 & After activity & 2.13 & 0.0006 \\
\hline 3 & Average & 1.93 & 0.0005335 \\
\hline
\end{tabular}

Assuming the heart beat rate and breathing rate relation is linear, the transfer function between the input heart beat rates to the output breathing rate output becomes 


$$
H(s)=\frac{B_{r}(s)}{H B_{r}(s)}=K_{r}=\frac{0.0005335}{1.93}=0.000276
$$

\section{The Proposed Controllers Design}

\subsection{Full State Feedback $H_{2}$ Controller Design}

Consider Figure 4 and assume that

$$
M=\left[\begin{array}{lll}
A & B_{1} & B_{2} \\
C_{1} & 0 & D_{12} \\
I & 0 & 0
\end{array}\right]
$$

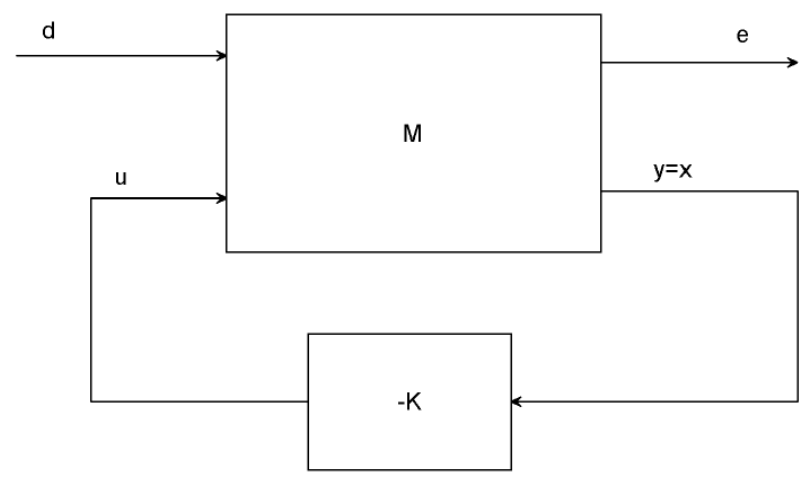

Figure 4 A full state feedback system.

From Equation (6),

$$
\begin{gathered}
\dot{x}=A x+B_{1} d(t)+B_{2} u(t) \\
e(t)=C_{1} x(t)+D_{12} u(t) \\
y(t)=x(t)
\end{gathered}
$$

Assuming that $d(t)$ is the white noise vector with unit intensity

$$
\left\|T_{e d}(s)\right\|_{H_{2}}^{2}=E\left(e^{T}(t) e(t)\right)
$$

Where

$$
e^{T} e=x^{T} C_{1}^{T} C_{1} x+2 x^{T} C_{1}^{T} D_{12} u+u^{T} D_{12}^{T} D_{12} u
$$

With Equation (7) and Equation (10), the minimization of $\left\|T_{e d}(s)\right\|_{H_{2}}$ is equivalent to the solution of the stochastic regulator problem. Setting 


$$
Q_{f}=C_{1}^{T} C_{1}, \quad N_{f}=C_{1}^{T} D_{12} \text { and } R_{f}=D_{12}^{T} D_{12}
$$

the optimal state feedback law is given by

$$
u=-K x
$$

Where

$$
K=R_{f}^{-1}\left(P B_{2}+N_{f}\right)^{T}
$$

And

$$
P\left(A-B_{2} R_{f}^{-1} N_{f}^{T}\right)+\left(A-B_{2} R_{f}^{-1} N_{f}^{T}\right)^{T} P-P B_{2} R_{f}^{-1} B_{a}^{T} P+Q_{f}-N_{f} R_{f}^{-1} N_{f}^{T}=0
$$

It should be noted that the gain $K$ is independent of the matrix B1. For this system the full state feedback gain matrix becomes

$$
K=\left(\begin{array}{ll}
0.0431 & 0.0227
\end{array}\right)
$$

\subsection{PID Controller}

A proportional-integral-derivative controller (PID controller) is a control system loop feedback mechanism (controller) widely used in industrial control systems. A PID controller attempts to correct the incorrectness between a measured variable and a desired set point by counting and then outputting a corrective demand that can adjust the currents accordingly and rapidly, to maintenance the erroneousness minimal.

The PID controller planning (algorithm) involves three separate parameters; the proportional, the integral and derivative values. The proportional value determines the reaction to the current error, the integral value determines the response based on the sum of recent errors, and the derivative value determines the response based on the rate at which the erroneousness has been changing. The weighted sum of these three effect is used to adjust the system output via a control element such as the position of a DC motor.

The proportional, integral, and derivative terms are summed to calculate the output of the PID controller. Defining $\mathrm{u}(\mathrm{t})$ as the controller output, the final term of the PID controller is:

$$
u(t)=K_{p} e(t)+K_{i} \int_{0}^{t} e(\tau) d \tau+K_{d} \frac{d e(t)}{d t}
$$

Using Ziegler-Nichols tuning method the value of the PID controller are

$$
K_{P}=86.3241 \quad K_{I}=759.4440 \quad K_{D}=42.7091
$$

\section{Result and Discussion}




\subsection{Comparison of the Portable Ventilator with Full State Feedback $H_{2}$ and PID Controllers for Step Change in Heart Beat}

The comparison simulation of the portable ventilator with full state feedback $H_{2}$ and PID controllers for a step change from (1.2 to 0.6) beats per second is shown in Figure 5 and Figure 6 below.

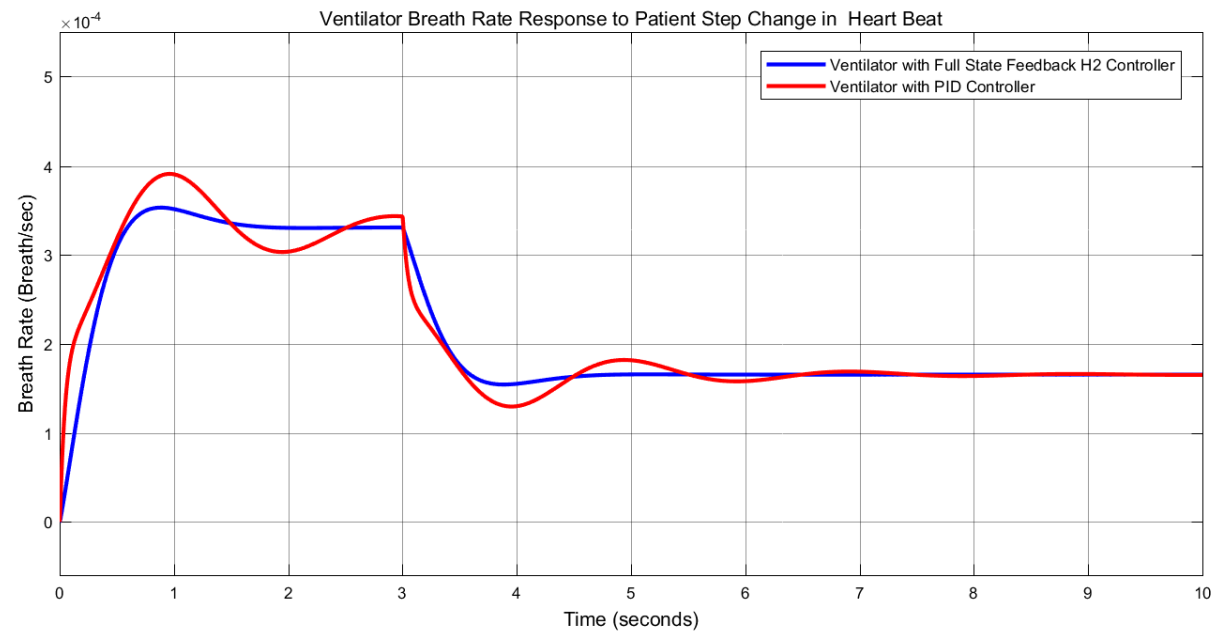

Figure 5 Step response

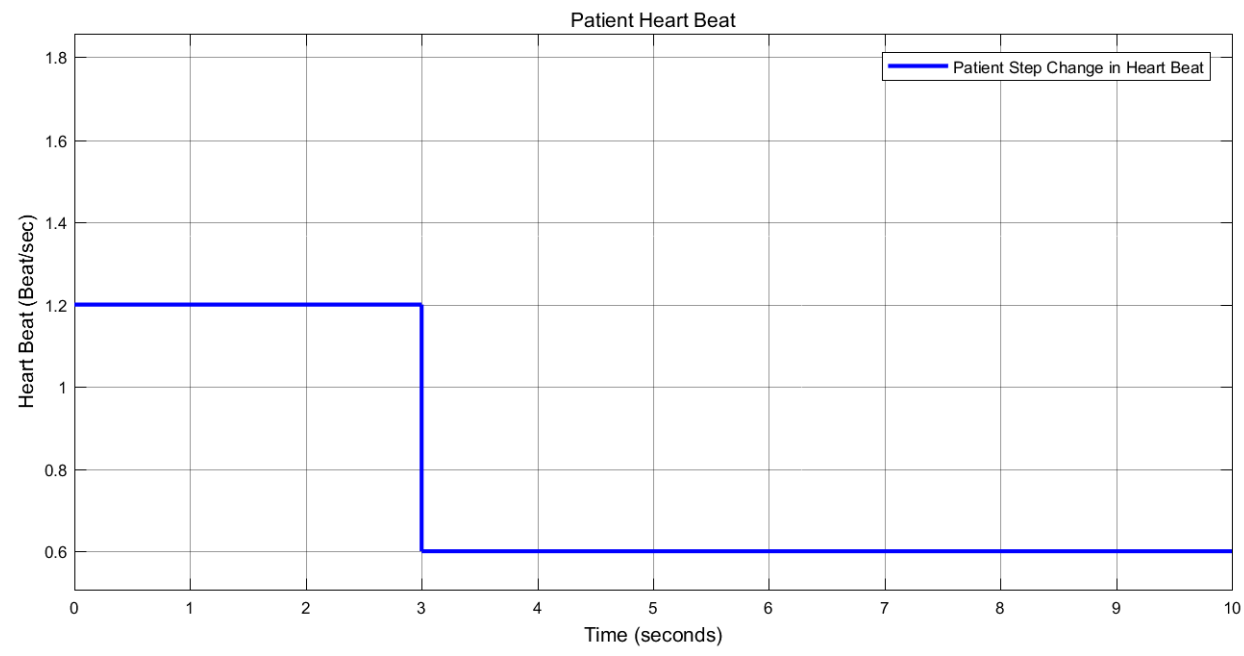

Figure 6 Heart beat input

The data of the rise time, percentage overshoot, settling time and peak value is shown in Table 3.

Table 3 Step response data

\begin{tabular}{|l|l|l|l|}
\hline No & Performance Data & Full state feedback H2 controller & PID controller \\
\hline 1 & Rise time & $0.4 \mathrm{sec}$ & $0.15 \mathrm{sec}$ \\
\hline 2 & Per. overshoot & $6 \%$ & $18.2 \%$ \\
\hline 3 & Settling time & $4.3 \mathrm{sec}$ & $7.5 \mathrm{sec}$ \\
\hline 4 & Peak value & 3.5 Beats per second & 3.9 Beats per second \\
\hline
\end{tabular}


As Table 3 shows that the portable ventilator with full state feedback $\mathrm{H} 2$ controller improves the performance of the system by minimizing the percentage overshoot and settling time.

\subsection{Comparison of the Portable Ventilator with Full State Feedback $\mathrm{H}_{2}$ and PID}

\section{Controllers for Random Change in Heart Beat}

The comparison simulation of the portable ventilator with full state feedback $\mathrm{H}_{2}$ and PID controllers for a random change from (0.6 to 1.8) beats per second is shown in Figure 7 and Figure 8 below.

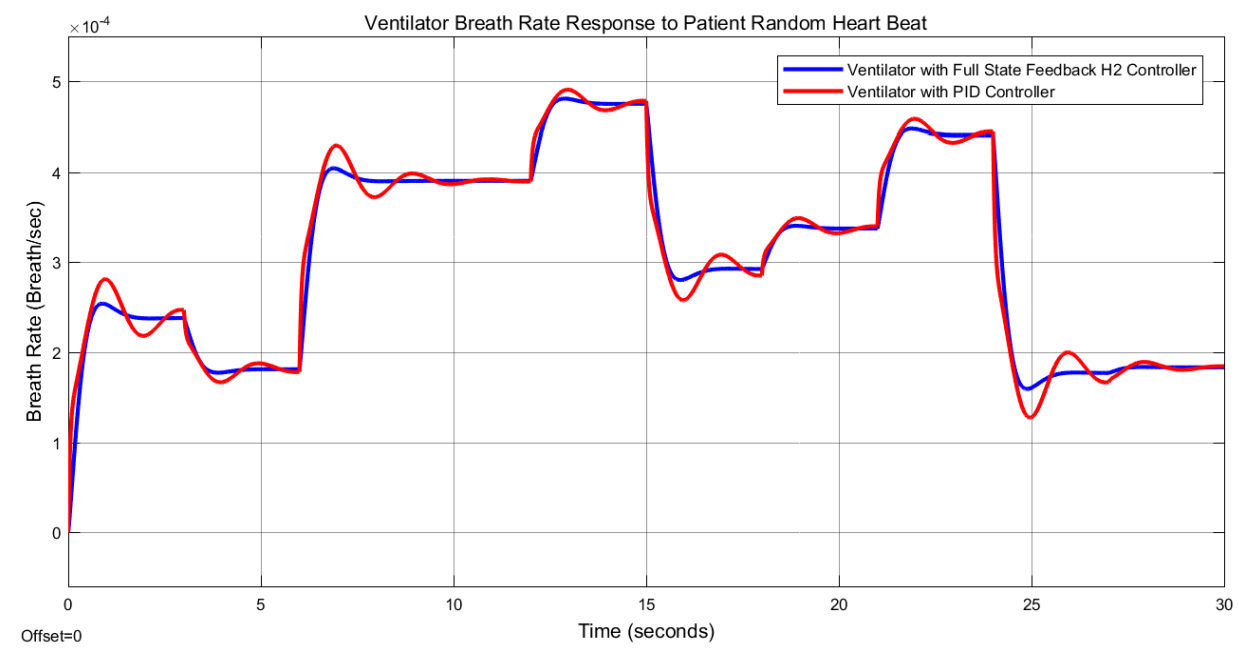

Figure 7 Random response

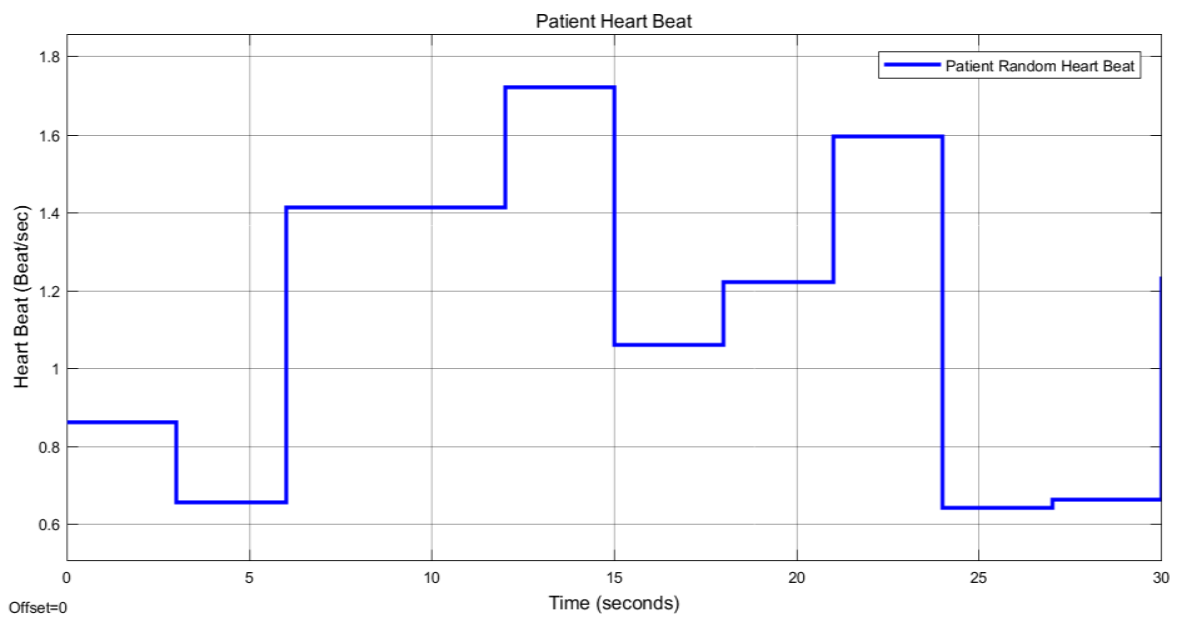

Figure 8 Heart beat input

As we seen from Figure 7, the portable ventilator with full state feedback $\mathrm{H} 2$ controller improves the performance of the system by minimizing the percentage overshoot and settling time. 


\section{Conclusion}

In this paper, designing and performance analysis of a low cost portable ventilator have been done for COVID-19 patients using Matlab Toolbox successfully. This system senses the patient heart beat and delivers the exact amount of volume of air to the patient lung with adjusted breathing rate. In order to improve the performance of the system PID and Full State Feedback H2 controllers have been used. The comparison simulation results of the system with the proposed controllers for a step change and a random change of the patient heart beat shows that the portable ventilator with full state feedback H 2 controller improves the performance of the system by minimizing the percentage overshoot and settling time.

\section{Reference}

[1]. Badre El Majid et al. "Preliminary Design of an Innovative, Simple and East to Build Portable Ventilator for COVID-19 Patients” Euro Mediterr J. Environ Integr, Vol. 5, Issue 2, 2020.

[2]. Onintza G. et al. 'Low Cost, Easy to Build Non Invasive Pressure Support Ventilator for Under Resourced Regions: Open Source Hardware Description, Performance and Feasibility Testing” European Respiratory Journal, DOI: 10.1183/13993003.00846-2020, 2020.

[3].B. Sai P. K. et al. "Design and Survey of a Modular Clinical Application Ventilator" International Journal of Psychosocial Re habitation, Vol. 24, Issue 2, pp. 5664-5670, 2020.

[4].Parag A. P. et al. "Improving Ventilator Rationing Through Collaboration with Experts on Resource Allocation” JAMA Netw Open, Vol. 3, Issue 6, 2020.

[5].Pearce JM. "A Review of Open Source Ventilators for COVID-19 and Future Pandemics" F1000Research, Vol. 9, Issue 219, 2020.

[6].Per Heiselberg "Natural Ventilation Design" International Journal of Ventilation, Vol. 2, Issue 4, pp. 295-312, 2016.

[7]. Abdul Mohsen A. H et al. "Design and Prototyping of a Low Cost Portable Mechanical Ventilator” Journal of Medical Devices, Vol. 4, Issue 2, 2010. 